\title{
Modeling enhanced firn densification due to strain softening
}

\author{
Falk M. Oraschewski ${ }^{1,2}$ and Aslak Grinsted ${ }^{2}$ \\ ${ }^{1}$ Department of Geosciences, University of Tübingen, Tübingen, Germany. \\ ${ }^{2}$ Physics of Ice, Climate, and Earth, Niels Bohr Institute, University of Copenhagen, Copenhagen, Denmark.
}

Correspondence: Falk M. Oraschewski (falk.oraschewski@uni-tuebingen.de)

\begin{abstract}
In the accumulation zone of glaciers and ice sheets snow is transformed into glacial ice by firn densification. Classically, this processes is assumed to solely depend on temperature and overburden pressure which is controlled by the accumulation rate. However, exceptionally thin firn layers have been observed in the high-strain shear margins of ice streams. Previously, it has been proposed that this firn thinning can be explained by an enhancement of firn densification due to the effect of strain softening inherent to power-law creep. This hypothesis has not been validated, and the greater firn densities in the presence of horizontal strain rates have not yet been reproduced by models. Here, we develop a model that corrects the firn densification rate predicted by classical, climate-forced models for the effect of strain softening. With the model it is confirmed that strain softening dominates the firn densification process when high strain rates are present. Firn densities along a cross section of the North-East Greenland ice stream (NEGIS) are reproduced with good agreement, validating the accuracy of the developed model. Finally, it is shown that strain softening has significant implications for ice core dating and that it considerably affects the firn properties over wide areas of the polar ice sheet, even at low strain rates. Therefore, we suggest that, besides temperature and accumulation rate, horizontal strain rates should generally be considered as a forcing parameter in firn densification modelling.
\end{abstract}

\section{Introduction}

Firn densification refers to the transformation of snow into glacial ice, which occurs in the uppermost layers of ice sheets and glaciers within their accumulation zones, when old snow, respectively firn, is buried under younger snow. The overburden pressure gradually increases and causes a densification of the firn. Large scale ice flow is not considered by firn models even though it is known that ice is a non-newtonian material where strain reduces the viscosity (Goldsby and Kohlstedt, 2001). In this paper we demonstrate that that this effect can have a substantial impact on firn densification.

Firn densification is conventionally divided into stages where different physical mechanisms dominate. Initially, the Newtonian grain-boundary sliding is dominant for densities of $\rho \leq 550 \mathrm{~kg} \mathrm{~m}^{-3}$, which is referred to as stage 1 of firn densification (Alley, 1987). In stage 2, at densities of $550 \mathrm{~kg} \mathrm{~m}^{-3} \leq \rho \leq 830 \mathrm{~kg} \mathrm{~m}^{-3}$, the non-Newtonian dislocation creep, also known as power-law creep, dominates the densification process until bubble close-off (BCO) (Maeno and Ebinuma, 1983). Beyond this point, defined as the firn-ice transition, the further densification is slowed as the enclosed gas-bubbles get compressed and eventually diffuse into the ice matrix (Salamatin et al., 1997). 
For a variety of glaciological studies, properties of the firn need to be known. For example, it is essential to know the firn air content for deriving the mass balance of an ice sheet from changes of its surface elevation, measured by satellite altimetry (e.g. Helsen et al., 2008). Ice core studies on the other hand require knowledge of the age difference $\Delta$ age between the water and the gas isotope records in the ice core, which is primarily determined by the BCO age (Schwander et al., 1997).

In many applications, these properties are determined by employing a firn densification model. Over the years, a wide range of models have been developed (e.g. Herron and Langway, 1980; Alley, 1987; Arnaud et al., 2000; Arthern et al., 2010), which are adapted for different climatic conditions and application areas (Lundin et al., 2017). Stevens et al. (2020) provided with the Community Firn Model (CFM) an open-source, modular model framework, which comprises the most established firn densification models within an one-dimensional Lagrangian modelling scheme and allows the implementation of additional firn processes as modular extensions.

While efforts are being made to directly model the physical processes that lead to a densification of firn (Alley, 1987; Arnaud et al., 2000), empirically tuned models, such as the Herron-Langway model (HL, Herron and Langway, 1980), are widely used. In this type of model, the densification rate equations are derived according to a few initial assumptions and subsequently tuned to fit density data from firn cores. Despite the different approaches, basically all existing models have in common that they merely consider temperature and accumulation rate as variable input parameters (Lundin et al., 2017). Therefore, these classical models will be denoted as climate-forced in the following.

The limitation to climatic forcing is not only insufficient for finding firn-model-tuning parameters that can be applied for the whole Greenlandic ice sheet (Simonsen et al., 2013), but it also contradicts with observations of stress, respectively the corresponding strain, affecting the densification of firn (Zumberge et al., 1960; Crary and Wilson, 1961; Gow, 1968; Kirchner et al., 1979; Alley and Bentley, 1988; Riverman et al., 2019). As a consequence existing firn models cannot sufficiently represent the reduced firn thickness which occurs in the high-strain shear margins of ice streams. However, the firn dynamics are important for understanding the dynamics of ice streams, as they potentially control their stability and contribute to the formation of shear margins troughs (Christianson et al., 2014; Riverman et al., 2019). The effect of horizontal strain rates on firn compaction moreover affects the firn air content in regions with strong ice dynamics and hence needs to be considered in mass balance studies (Horlings et al., 2021).

The reduced firn thickness due to strain is explained by two processes: Horizontal divergence and strain softening.

Horizontal divergence of velocities causes a simple horizontal stretching and thus a vertical thinning of the firn. This effectively reduces the overburden load. The firn density itself is however not directly affected. Morris et al. (2017) accounted for this thinning in their firn model by introducing a correction factor that scales the vertical compaction strain rate according to the expected vertical thinning. A similar layer-thinning scheme was implemented into the CFM by Horlings et al. (2021) as an optional module.

Strain-softening was first suggested by (Alley and Bentley, 1988) to accelerate the firn densification in the presence of horizontal strain rates. Alley and Bentley explain it by an enhancement of power-law creep, which as a non-Newtonian (pseudoplastic) process scales with the square of the effective stress. Hence, a stress applied in horizontal direction can also accelerate the firn densification in vertical direction by reducing the effective viscosity. Strain softening mainly affects stage 2 of firn 
densification, as this is where power-law creep is dominant (Alley and Bentley, 1988). This interpretation was supported by Riverman et al. (2019), who observed that the variation of firn thickness, recorded along a cross-section of the North-East Greenland Ice Stream (NEGIS) by active seismic surveying, scales well with the net strain along the flow path of the past 400 years.

Despite the observational evidence, firn densification models used for polar ice sheets do not capture the effect of strain softening. Based on a constitutive equation by Duva and Crow (1994) describing the behavior of porous media under powerlaw creep, Gagliardini and Meyssonnier (1997) have developed a flow model for alpine glaciers, which inherently considers compaction, and in particular strain softening, of the firn. This approach requires knowledge of the internal, horizontal stresses from flow modeling and is widely used in studies of alpine glaciers (Lüthi and Funk, 2000; Zwinger et al., 2007; Licciulli et al., 2020), but has not been applied to polar ice sheets.

In this paper we aim to model the effect of strain softening in the firn. In order to do so, a correction factor is derived that can be applied to correct the firn densification rate, predicted by any climate-forced firn densification model, for the impact of horizontal strain rates.

\section{Theory}

75 A firn densification model in a Lagrangian formulation expresses the densification rate of a firn layer as a function of external forcing parameters and internal parameters, representing its current state. The external parameters are generally time-variable. In a climate-forced model these are the temperature $T$ and accumulation rate $\dot{b}$, respectively the thereof derived overburden load $\sigma$. As an internal parameter most firn models only consider the current density $\rho$ of the firn layer. Newly formed snow layers at the surface further require the initial snow density $\rho_{0}$ as a boundary condition. For a specific site this is however in most applications assumed to be constant with time. The densification rate of a climate-forced model (denoted with the subscript c) is hence given in the form of

$$
\left(\frac{\mathrm{D} \rho}{\mathrm{D} t}\right)_{\mathrm{c}}=f(T, \sigma, \rho)
$$

with the time $t$. Following Morris et al. (2017) this densification rate relates to a corresponding volumetric strain rate $\dot{\varepsilon}$. As this type of model only considers densification in vertical direction the volumetric strain rate matches the vertical component $\dot{\varepsilon}_{z z, \mathrm{c}}$, which hence reads as

$\dot{\varepsilon}_{z z, \mathrm{c}}=-\frac{1}{\rho}\left(\frac{\mathrm{D} \rho}{\mathrm{D} t}\right)_{\mathrm{c}}$.

Because no additional horizontal strain rates are considered to affect firn densification in a climate-forced model, the strain rate tensor of such a model at a specific point within the firn is expressed by

$$
\dot{\varepsilon}_{\mathrm{c}}=\left(\begin{array}{ccc}
0 & 0 & 0 \\
0 & 0 & 0 \\
0 & 0 & \dot{\varepsilon}_{z z, \mathrm{c}}
\end{array}\right) .
$$


However, horizontal flow will also strain the firn. Assuming that the vertical shear components $\left(\dot{\varepsilon}_{x z}, \dot{\varepsilon}_{y z}\right)$ remain zero, the strain rate tensor becomes

$\dot{\varepsilon}=\left(\begin{array}{ccc}\dot{\varepsilon}_{x x} & \dot{\varepsilon}_{x y} & 0 \\ \dot{\varepsilon}_{x y} & \dot{\varepsilon}_{y y} & 0 \\ 0 & 0 & \dot{\varepsilon}_{z z}\end{array}\right)$,

where the horizontal components $\left(\dot{\varepsilon}_{x x}, \dot{\varepsilon}_{x y}, \dot{\varepsilon}_{y y}\right)$ generally affect the vertical strain rate $\dot{\varepsilon}_{z z}$ by the effects of horizontal divergence and strain softening, such that $\dot{\varepsilon}_{z z} \neq \dot{\varepsilon}_{z z, \mathrm{c}}$. More particularly this means that the corresponding densification rate

$$
\frac{\mathrm{D} \rho}{\mathrm{D} t}=-\dot{\varepsilon}_{z z} \rho
$$

is in consequence also altered by the horizontal strain rate components. Inserting Eq. 2 into Eq. 5 gives

$$
\frac{\mathrm{D} \rho}{\mathrm{D} t}=\frac{\dot{\varepsilon}_{z z}}{\dot{\varepsilon}_{z z, \mathrm{c}}}\left(\frac{\mathrm{D} \rho}{\mathrm{D} t}\right)_{\mathrm{c}}
$$

Accordingly, the densification rate with strain softening can be computed from the densification rate predicted by a climateforced model when a scale factor given by the ratio of the corresponding vertical strain rate components is known. We aim in the following to determine this scale factor.

\subsection{The scale factor}

In firn stage 2, where power-law creep is dominant, firn densification can be modeled by the constitutive relation $\dot{\varepsilon}_{z z}=A \sigma^{n}$ with the creep factor $A$, representing the temperature impact, and the creep exponent $n$. The power-law creep equation can be generalized analogously to the derivation of Nye's generalization of Glen's flow law (Nye, 1957; Greve and Blatter, 2009, Ch. 4), with the only difference being that stress is used instead of the stress deviator. This adaptation is valid without limitations and avoids the assumption of incompressibility that would be implied by the use of the stress deviator. The additional assumption of isotropy made in Nye's derivation also can be followed as firn is generally isotropic. The generalized power-law creep equation then reads as

$110 \dot{\varepsilon}_{z z}=\frac{1}{2 \eta} \sigma$,

where the vertical strain rate of the densification is proportional to the causative overburden load, scaled by an effective viscosity $\eta$, given by

$\eta=\left[2 A^{1 / n} \dot{\varepsilon}_{\mathrm{E}}^{m}\right]^{-1}$

This effective viscosity again depends on the effective strain rate $\dot{\varepsilon}_{\mathrm{E}}=\left[\frac{1}{2}\left(\dot{\varepsilon}_{x x}^{2}+\dot{\varepsilon}_{y y}^{2}+\dot{\varepsilon}_{z z}^{2}\right)+\dot{\varepsilon}_{x y}^{2}\right]^{1 / 2}$ with the exponent $m=$

$1151-1 / n$. These equations illustrate, how the horizontal strain rates lead to a decrease of the effective viscosity, which again for the same load gives rise to a higher vertical strain rate. This is exactly what the term strain softening denotes. 
As the enhanced vertical strain rate is dependent on the effective viscosity which again depends on the vertical strain rate itself, its derivation is not straight forward. Eqs. 7 and 8 can be formulated similarly for the case of no horizontal strain. We note that the load and the creep factors are not affected by the horizontal strain rates and therefore must cancel out when we take the ratio in eq. 6 to obtain the scale factor.

The effective viscosity of a purely climate-forced model $\eta_{\mathrm{c}}$ will be overestimated, as it neglects the effect of strain softening by horizontal strain rates. The effective strain rate according to the reduced strain rate tensor (3) is $\dot{\varepsilon}_{\mathrm{E}, \mathrm{c}}=\left[\frac{1}{2} \dot{\varepsilon}_{z z, \mathrm{c}}^{2}\right]^{1 / 2}$, which leads to a reduced vertical strain rate of

$\dot{\varepsilon}_{z z, \mathrm{c}}=\frac{1}{2 \eta_{\mathrm{c}}} \sigma$.

By dividing Eq. 7 with Eq. 9, we obtain the scale factor and note that it is given by the ratio between the effective viscosity of the climate forced model and the 'true' effective viscosity:

$\frac{\dot{\varepsilon}_{z z}}{\dot{\varepsilon}_{z z, \mathrm{c}}}=\frac{\eta_{\mathrm{c}}}{\eta}$

Inserting the effective viscosities according to Eq. 8 with the corresponding effective strain rates gives

$\frac{\dot{\varepsilon}_{z z}}{\dot{\varepsilon}_{z z, \mathrm{c}}}=\left(\frac{\dot{\varepsilon}_{x x}^{2}+\dot{\varepsilon}_{y y}^{2}+\dot{\varepsilon}_{z z}^{2}+2 \dot{\varepsilon}_{x y}^{2}}{\dot{\varepsilon}_{z z, \mathrm{c}}^{2}}\right)^{m / 2}$,

which can be rewritten in the form of

$r_{\mathrm{V}}=\left(r_{\mathrm{H}}^{2}+r_{\mathrm{V}}^{2}\right)^{m / 2}$

whereby the following two variables are defined:

$r_{\mathrm{V}}:=\frac{\dot{\varepsilon}_{z z}}{\dot{\varepsilon}_{z z, \mathrm{c}}}$,

$r_{\mathrm{H}}:=\left(\frac{\dot{\varepsilon}_{x x}^{2}+\dot{\varepsilon}_{y y}^{2}+2 \dot{\varepsilon}_{x y}^{2}}{\dot{\varepsilon}_{z z, \mathrm{c}}^{2}}\right)^{1 / 2}$.

135 While all components of $r_{\mathrm{H}}$ are known, which are the horizontal strain rates derived from velocity fields and the vertical strain rate of the climate-based model, the variable $r_{\mathrm{V}}$ corresponds exactly to the scale factor that is sought. Hence, Eq. 12 needs to be solved for $r_{\mathrm{V}}$ in order to obtain the scale factor for correcting the original densification rate of a climate-forced model for the effect of strain softening.

The solution of Eq. 12 depends on the creep exponent. Dislocation creep is the key process driving densification in the second firn stage (Maeno and Ebinuma, 1983). In this paper we therefore use a creep exponent of $n=4$, characteristic for dislocation creep (Goldsby and Kohlstedt, 2001; Bons et al., 2018). At this point only the solution shall be given, because its 
derivation would exceed the scope of the paper. We find,

$$
\begin{aligned}
& \kappa_{1}=\left[9 r_{\mathrm{H}}^{8}+\sqrt{81 r_{\mathrm{H}}^{16}+768 r_{\mathrm{H}}^{18}}\right]^{1 / 3}, \\
& \kappa_{2}=\left[1+8 r_{\mathrm{H}}^{2}+\sqrt[3]{\frac{32}{9}} \kappa_{1}-\frac{\sqrt[3]{\frac{8192}{3}} r_{\mathrm{H}}^{6}}{\kappa_{1}}\right]^{1 / 2}, \\
& \kappa_{3}=\left[\frac{1}{2}+4 r_{\mathrm{H}}^{2}-\frac{\kappa_{1}}{\sqrt[3]{18}}+\frac{\sqrt[3]{\frac{128}{3}} r_{\mathrm{H}}^{6}}{\kappa_{1}}+\frac{1+12 r_{\mathrm{H}}^{2}+24 r_{\mathrm{H}}^{4}}{2 \kappa_{2}}\right]^{1 / 2}, \\
& r_{\mathrm{V}}=\left[\frac{1}{4}+\frac{1}{4} \kappa_{2}+\frac{1}{2} \kappa_{3}\right]^{1 / 2} \cdot
\end{aligned}
$$

This scale factor is the strain softening enhancement. An alternative, simpler solution for $n=3$ is derived in (Oraschewski,

\subsection{Regularization}

The densification in climate-forced models, such as the HL model, is characterized by an exponential decay towards the density of solid ice. The vertical strain rate $\dot{\varepsilon}_{z z, \mathrm{c}}$ in such models goes to zero as the density approaches $917 \mathrm{~kg} \mathrm{~m}^{-3}$. This means that $r_{H}$, and thus the scale factor goes towards infinity. This singularity causes an unphysical behavior of the strain softening model, where the density of ice is approached almost instantaneously at a certain point.

To circumvent this issue, a regularization is introduced. Inspired by regularized Glen's flow law (Greve and Blatter, 2009, Ch. 4) a residual strain rate $\dot{\varepsilon}_{0}$ is added to the vertical strain rate to ensure a finite correction factor:

$r_{\mathrm{H}}:=\left(\frac{\dot{\varepsilon}_{x x}^{2}+\dot{\varepsilon}_{y y}^{2}+2 \dot{\varepsilon}_{x y}^{2}}{\left(\dot{\varepsilon}_{z z, \mathrm{c}}+\dot{\varepsilon}_{0}\right)^{2}}\right)^{1 / 2}$.

Leaving the perspective of firn densification modeling, the residual strain rate can be associated with the general thinning of firn and ice layers in ice sheets that is induced by the flow of ice towards the ice sheet margins. While the densification part of the vertical strain rates approaches zero, this contribution remains finite. The corresponding vertical strain rate is in the order of $\dot{\varepsilon}_{0} \approx-2 \times 10^{-4} \mathrm{yr}^{-1}$, which we choose as the residual strain rate in the following. The derivation of this residual strain rate can be found in (Oraschewski, 2020).

\section{Implementation}

The strain softening scale model is implemented as an optional module into the CFM by Stevens et al. (2020). Supported by its Lagrangian modelling scheme, the implementation itself is rather simple and computationally cheap. The uncorrected vertical strain rate is computed from the initial densification rate according to Eq. 2 using a classical climate-forced densification model. Together with the input data for the horizontal strain rates the variable $r_{\mathrm{H}}$ can then be computed by Eq. 16, from which the correction factor of the vertical strain rate is computed with Eq. 15. 

horizontal strain rates are loaded in the form of the principal horizontal strain rates (see e.g. Nye, 1959). In this way the shear components disappear, such that the amount of input data is reduced without the loss off any relevant information.

The strain-softening model is only applied in the second stage of firn densication for $\rho>550 \mathrm{~kg} \mathrm{~m}^{-3}$ as power-law creep is thought to dominate firn densification only in this range, while the Newtonian grain-boundary sliding is driving the densification process before. Although a smooth transition between the two processes over a range of densities is expected (Hörhold et al., 2011), its exact course is unknown and a sharp transition is assumed in our present implementation. Nonetheless, attempts to implement a smooth transition did not affect the model output significantly (not shown).

Within the CFM framework the strain softening model can be executed in combination with any of the implemented climateforced firn densification models. In the following model experiments, we will be using the Herron-Langway model (Herron and Langway, 1980) in its stress-based formulation as the input model. While the HL model on one hand is capable of reproducing the firn densities in the investigated NEGIS region accurately, its stress-based formulation additionally considers potential strain-induced changes of the overburden load, which an accumulation-based formulation does not capture.

\section{Data}

Modeling strain softening requires knowledge about the horizontal strain rates. For the modeling experiments conducted in this paper, horizontal strain rates are computed from surface velocity maps of the Greenlandic (GrIS) and Antarctic ice sheet (AIS) using the logarithmic strain rate computation method as discussed by Alley et al. (2018). Nominal computation of the strain rates proved however to be sufficient as difference between the two computation methods were smaller than the uncertainty induced by the velocity data itself.

For the GrIS horizontal strain rates were computed from the MEaSUREs Multi-year Greenland Ice Sheet Velocity Mosaic (Joughin et al., 2016) by Joughin et al. (2018), which has a spatial resolution of $250 \mathrm{~m} \times 250 \mathrm{~m}$. For the AIS the MEaSUREs InSAR-Based Antarctica Ice Velocity Map, Version 2 (Rignot et al., 2017) by Rignot et al. (2011) and Mouginot et al. (2012) with a spatial resolution of $450 \mathrm{~m} \times 450 \mathrm{~m}$ is used.

Before determining the strain rates from the velocity fields, a Gaussian filter is applied on the velocity maps to reduce the impact of processing artifacts in the data, which likely were caused by combining velocity data from different sources for producing these velocity fields. These artifacts appear as a grid structure in the strain rate products and clearly do not represent any physical information, but would lead to an overestimation of the horizontal strain rates, if not removed. In the GrIS velocity data a Gaussian filter with a standard deviation of 2 pixels was applied. For the AIS we use a variable Gaussian filter with standard deviations between $2-10$ pixels. Regions with poor data coverage and higher reported uncertainties e.g. in the polar hole - are smoothed more. The smoothing reduce the effective spatial resolution of the velocity grid, which can hide the maximum local strain in shear margins. However, this is not a major concern as km-scale variations of horizontal strain rates average out over the firn age. 
For validating the strain softening model, firn density data recorded at the NEGIS in the vicinity of the EGRIP ice core site is used. As suggested by Vallelonga et al. (2014) the NEGIS with its high-strain shear margins offers excellent opportunities for studying firn densification processes. The data reproduced in this study comprises a $37 \mathrm{~km}$-long cross section of the NEGIS firn densities recorded with active seismic surveying by Riverman et al. (2019) and the density of the NEGIS firn core (Vallelonga et al., 2014). Their locations are shown in Fig. 1. Additionally, the density of the EGRIP S5 2019 shear margin firn core is modeled with the intent to compare the model with directly measured firn density data from a high-strain area. However, this data is unfortunately not available yet, as the firn core is stored at the EGRIP station and is not accessible, because of COVID-19-related restrictions of field work.

The horizontal strain rates that the firn at these sites has experienced in the past, are computed by step-wise backtracing their position according to the velocity field with a monthly resolution and interpolating the computed horizontal strain rate components to these points at every time step. We force the model with a constant temperature of $-29.9^{\circ} \mathrm{C}$. This is the seasonality-corrected mean of the $10 \mathrm{~m}$ temperature recorded between June 2019 and January 2021 at the PROMICE weather station at EGRIP (Fausto and van As, 2019). Using a constant temperature input is justified, because we are mainly interested in firn processes occurring below a depth of $10 \mathrm{~m}$, where seasonal and inter-annual variability of temperature is smoothed out by heat conduction. Further, we do not expect a significant spatial variability of temperature over this relatively small study region. As accumulation rate input we use the values derived by Riverman et al. (2019) from the Accumulation Radar of an Operation IceBridge flightline (Paden et al., 2014, updated 2018) crossing the NEGIS density profile, see Fig. 1b. We extrapolate the accumulation rate from the flight line to the sites where densification is modelled using nearest point interpolation.

The effect of strain softening on firn densification is not only studied on local, but also on ice sheet wide scales. For this purpose the output data of the regional climate model HIRHAM5, forced by the ERA-Interim reanalysis product (Dee et al., 2011), is employed as climatic forcing. For the GrIS the mean of the precipitation and surface temperature output between 1980 and 2014 is used (Langen et al., 2017; Mottram et al., 2017) and has a spatial resolution of $0.05^{\circ}$, respectively $\sim 5 \mathrm{~km}$. For the AIS the mean surface mass balance and $10 \mathrm{~m}$ temperature output between 1980 and 2017 are used (Hansen et al., 2021), which have a resolution of $0.11^{\circ}$, respectively $\sim 12.5 \mathrm{~km}$.

Newly formed surface layers are set to a density of $315 \mathrm{~kg} \mathrm{~m}^{-3}$ in all model runs, following Fausto et al. (2018). This matches well with measured surface densities in the NEGIS region (Schaller et al., 2016). Although this assumption is certainly not valid over the whole GrIS and AIS, the potential bias can be neglected in our ice sheet wide experiments, as the main interest lies in the identification of the relative changes in the predicted firn properties between models that do and do not consider strain softening. 


\section{Results and Discussion}

\subsection{Sensitivity test}

In order to understand how strain softening behaves under different dynamic conditions a sensitivity test was conducted. For the climatic conditions present at the EGRIP ice core site in the center of NEGIS the firn density and firn age was modeled for a range of effective horizontal strain rates between $\dot{\varepsilon}_{\mathrm{E}, \mathrm{H}}=0$ and $\dot{\varepsilon}_{\mathrm{E}, \mathrm{H}}=7 \times 10^{-3} \mathrm{yr}^{-1}$.

The strain dependent age profile of the firn is shown in Fig. 2a. The black contour lines additionally indicate the transition between first and second firn stage at the critical density of $550 \mathrm{~kg} \mathrm{~m}^{-3}$ and the firn-ice transition at the BCO density of $830 \mathrm{~kg} \mathrm{~m}^{-3}$. The depth of the critical density remains unaffected, as the strain enhancement model is only enabled in the second firn stage. Below the critical density the densification occurs more rapidly as the effective horizontal strain rate is increased, and the firn-ice transition occurs at a shallower depth. This reduction is strongest at low $\dot{\varepsilon}_{\mathrm{E}, \mathrm{H}}$ and steadily gets weaker when strain rates rise. For example the thinning at a strain rate of about $1.2 \times 10^{-3} \mathrm{yr}^{-1}$ is already half as big as in the case of $\dot{\varepsilon}_{\mathrm{E}, \mathrm{H}}=7 \times 10^{-3} \mathrm{yr}^{-1}$. Hence, the sensitivity of firn densification is greatest at low strain rates.

The picture is similar for the sensitivity of the firn age at a certain depth and for the BCO age, represented in Fig. 2a by the age of the firn at the BCO density line. Again both quantities are most sensitive to the effect of strain softening at low strain rates. The shift of the firn age at a given depth is however rather weak with a decrease of the firn age by up to $10 \%$ for $\dot{\varepsilon}_{\mathrm{E}, \mathrm{H}}=7 \times 10^{-3} \mathrm{yr}^{-1}$. The BCO age in contrast is strongly affected by the horizontal strain rates with a decrease of more than $50 \%$ at the highest strain rate values in this test.

In summary, both the $\mathrm{BCO}$ depth as well as the $\mathrm{BCO}$ age are strongly affected by high strain rates, but even low strain rates of less than $1 \times 10^{-3} \mathrm{yr}^{-1}$ do affect the firn properties considerably.

\subsection{Comparison with firn cores}

The firn density profiles at the sites of the NEGIS firn core and the EGRIP S5 2019 firn core are modeled with the HL model by first considering no strain and subsequently by additionally activating the modules for horizontal divergence (not shown), strain softening and finally adding a further correction for strain softening, which will be introduced in the following.

In Fig. $2 b$ the results for the NEGIS firn core, drilled at the site of the EGRIP station, are shown and compared to the data. As the effective horizontal strain rate is small at this site, the differences between the various model setups are also small. The no strain-model already reproduces the density data with good agreement. While horizontal divergence only contributes to a reduction of the firn thickness by $1 \mathrm{~m}$, strain softening thins the firn by additional $6 \mathrm{~m}$.

As the no-strain model already matches the data, the strain softening model underestimates the firn thickness. This can be explained by the fact that the no-strain HL model has been empirically tuned to the density profiles at a range of sites. Thus, it implicitly also accounts for some effective strain rate that is typical for these sites. The mean effective horizontal strain rate at the sites of the firn cores, used to calibrate the HL model, amounts to $\dot{\varepsilon}_{\mathrm{cor}}=4 \times 10^{-4} \mathrm{yr}^{-1}$. Hence, a corresponding strain softening contribution can be expected to be captured by the HL model, which in regard of the sensitivity test results is considerable. 
We therefore apply a correction that reduces the effective horizontal strain rate input into the strain softening model, by subtracting a value of $\dot{\varepsilon}_{\text {cor }}$ from the effective horizontal strain rate, respectively by setting lower strain rates to 0 , as the effective horizontal strain rate may not become negative. Because $\dot{\varepsilon}_{\text {cor }}$ almost matches the effective horizontal strain rate at the EGRIP site, the correction nearly completely rules out the effect of strain softening for this site and only the contribution of horizontal divergence is what remains.

Although the shear margin firn density data of the S5 2019 firn core is not available, the corresponding modeled firn density profiles are shown in Fig. 2c as an example for a high-strain site. The modeled density profile for the cases of no strain resembles the profiles at the EGRIP site. While horizontal divergence again only slightly alters the firn profile, strain softening causes a significant reduction of the firn thickness by $28 \mathrm{~m}$ and thereby causes the kink at the critical density to disappear. At this high-strain site the previously introduced correction factor only has little affect on the firn density profile, which is caused by the lower sensitivity of the firn densification to changes of the effective horizontal strain rate at high values.

\subsection{Validation with NEGIS firn density cross section}

As a next step the firn densities recorded along a cross section of NEGIS by (Riverman et al., 2019) are reproduced. The original data is shown in Fig. 3a with the firn-ice transition being indicated by the white contour line. In this profile the increased firn density within the shear margins of NEGIS can clearly be seen, causing a reduction of the firn thickness by 20 to $30 \mathrm{~m}$.

In Fig. $3 b$ the density profile is modeled with the corrected strain softening model at the locations of the individual seismic survey sites as shown in Fig. 1b, according to the forcing parameters displayed in Fig. 3c, which are the accumulation rate $\dot{b}$ and the effective horizontal strain rates experienced along the flow path, illustrated as the mean effective horizontal strain rate over the firn age, $\overline{\dot{\varepsilon}_{\mathrm{E}, \mathrm{H}}}$. For the temperature a constant value of $-29.9^{\circ} \mathrm{C}$ was assumed. Additional to the results of the corrected strain softening model and its BCO contour, the latter is also displayed for the cases of no strain, horizontal divergence, and the uncorrected strain softening model.

In the case of no strain, the BCO line represents the impact of the accumulation rate variability alone. It shows that the observed density peaks in the shear margins cannot be attributed to the accumulation pattern. In contradistinction to the observed lower firn thickness, the higher snow accumulation in the shear margin would even promote an increase of firn thickness.

Similar conclusions need to be drawn for the effect of horizontal divergence, as the corresponding BCO line only differs slightly from the case of no strain. Horizontal divergence merely affects the firn thickness by a few meters, whereat no clear trend for a firn thinning can be seen, but instead firn thickness also increases where velocities are actually converging as it is for example the case at the S5 2019 firn core site, indicated by the left vertical line. If velocities diverge at one place, they must converge elsewhere. Therefore, horizontal divergence cannot explain a pure firn thinning pattern, but always results in an increase of firn thickness nearby and consequently it particularly cannot explain the reduced firn thickness in the shear margins of ice streams.

The increased firn density in the shear margins with the respective lowering of the BCO depth can only be reproduced, when strain softening is included into the model. In this case the extent of the density peaks can be reproduced well, which validates the model and supports the idea that the enhanced firn densification rates at high strain rates are caused by strain softening. 
Comparing the strain softening cases with and without subtracting the correction factor of $\dot{\varepsilon}_{\text {cor }}=4 \times 10^{-4} \mathrm{yr}^{-1}$ along the cross section, it is becomes notable, that even such a small contribution can considerably alter the modeled firn thickness by up to $5 \mathrm{~m}$. As the sensitivity of firn densification to strain softening is highest at low strain rates, the correction also has the biggest impact in-between and outside of the shear margins, where strain rates are low. Within the high-strain shear margins the correction on the contrary has only very little effect.

The main difference between data and model lies in an apparent shift of the modeled firn density profile of $2 \mathrm{~km}$ towards south-east. No, processing error that would explain such a shift could be identified, neither for the model nor the data. Instead, the shift could point towards a potential movement of the ice stream position over time, which would not be represented in the model as the past horizontal strain rates are inferred from present day surface velocities, whereby the assumption of steady state conditions is implicitly made.

\subsection{Firn properties along NEGIS}

In Fig. 4a the modeled change of the firn thickness is compared with the elevation of the ice sheet surface along the seismic survey line. The shear margin troughs resemble the modeled reduction of the firn thickness with regard to depth, extent and location, suggesting that they are formed by a collapse of the firn layer due to strain softening. However, as the agreement is not perfect, other factors, such as upstream effects, accumulation variations and the sub-glacial topography, must also alter the surface elevation and the structure of the shear margins troughs.

Previously, the expected depth of the shear margin troughs was estimated by integrating the vertical strain rate caused by horizontal divergence along the flow line, giving a total strain of -0.1 which translates into a trough depth of 200 to $300 \mathrm{~m}$ (Fahnestock et al., 2001). Our results in contrary indicate that horizontal divergence in the firn does not contribute to the trough formation. Although our study focuses on the firn layer, this conclusion can be extended to the ice layer below. Because the firn thinning matches the depression of the surface topography, the ice layer itself has an approximately flat surface, suggesting that no thinning is occurring within. Instead, it indicates that the pattern of horizontal strain rates must be changing with depth. This depth variable horizontal strain rate in turn might have an impact on strain softening. The presented model however assumes that horizontal strain rate are constant with depth, the role of its depth variability hence needs to be investigated in future studies.

The BCO age along the profile is shown in Fig. 4b. While the firn reaches an age of up to $400 \mathrm{yr}$ in the center of the ice stream, the firn-ice transition in the shear margin already takes place after about $200 \mathrm{yr}$. This means that in the shear margins the densification rate is effectively doubled by strain softening. The BCO age is reduced by $50 \%$ over a distance of only $5 \mathrm{~km}$, whereas the climatic forcing on firn air processes can be expected to vary very little over such short distances. For this reason, we suggest to exploit the shear margins as a natural laboratory for firn air studies, because Characteristic parameters of firn air processes can potentially be better constrained by exploiting this setup. 
https://doi.org/10.5194/tc-2021-240

Preprint. Discussion started: 22 September 2021

(c) Author(s) 2021. CC BY 4.0 License.

\section{(c) (i)}

\subsection{Implications for ice core dating}

The gas enclosed in bubbles at the $\mathrm{BCO}$ is younger than the surrounding ice. This introduces a difference between the age of the ice matrix and the gas in an ice core $(\Delta$ age). Accurate models of densification are thus important for synchronizing ice core records. A precise relative timing is necessary to understand the sequence of events and the physical mechanisms behind past changes in climate (Pedro et al., 2012). E.g. Buizert et al. (2015) finds that abrupt Greenland warming events lead corresponding Antarctic cooling onsets by $218 \pm 92$ years. This conclusion hinges on the estimated $\Delta$ age at the WAIS Divide ice core. In contrast to this, Svensson et al. (2020) finds a $122 \pm 24$ year lag between Greenland and Antarctic ice core records using a volcanic synchronization that does not rely on densification processes. To gauge the potential impact of strain softening at this site we test the sensitivity to an effective strain rate of $1 \times 10^{-3} \mathrm{yr}^{-1}$ using WAIS Divide climate conditions. For Holocene climate we find that strain softening reduces the BCO age by $23 \%$ (from 309 to 238 years) and BCO depth by $20 \%$. For Last Glacial Maximum conditions $\left(-41^{\circ} \mathrm{C}\right.$ and $\left.0.1 \mathrm{myr}^{-1}\right)$ the $\mathrm{BCO}$ age is reduced by $33 \%$ or 209 years and $\mathrm{BCO}$ depth by $29 \%$. The impact of strain softening therefore depends on the climatic forcing at the site and can alter over time even if the effective horizontal strain rate remains constant. For the WAIS Divide site the BCO age reduction by a moderate strain rate decreased from 209 to 71 years between the Last Glacial Maximum and the Holocene. This decrease is therefore on the order of the observed time lag between Greenland and Antarctic ice core records and needs to be considered for synchronizing ice core records by gas isotopes.

In classical climate-forced densification models the densification rate and thus $\Delta$ age is almost entirely determined by surface temperature and accumulation rate. Buizert et al. (2021) exploit this to infer past surface temperature from estimates of $\Delta$ age and accumulation rate. However, our modelling shows that horizontal strain from large scale ice flow lead to enhanced densification rates and should also be taken into account. A complication when modelling past densification rates is that large scale ice flow could have changed over time.

\subsection{Firn properties of the polar ice sheets}

Finally, the ice sheet wide impact of strain softening on firn densification is studied. For this purpose, steady state firn density profiles were modeled using the HL model with the strain softening extension for various combinations of forcing parameters that cover the range of climatic conditions and effective horizontal strain rates that are present over the GrIS and the AIS according to the HIRHAM5 output data and the satellite based velocity fields products.

For Greenland, temperature was altered between $-29^{\circ} \mathrm{C}$ and $-17^{\circ} \mathrm{C}$ in steps of $2^{\circ} \mathrm{C}$, accumulation rate was logarithmically increased in 7 steps from $75 \mathrm{~mm} / \mathrm{yr}$ to $1 \mathrm{~m} / \mathrm{yr}$ and the effective horizontal strain rate was increased in steps of $1 \times 10^{-3} \mathrm{yr}^{-1}$ from 0 to $7 \times 10^{-3} \mathrm{yr}^{-1}$, giving 392 different combinations of forcing parameters in total. For Antarctica temperature was linearly increased from $-60^{\circ} \mathrm{C}$ to $-10^{\circ} \mathrm{C}$ in 6 steps, accumulation rate was again logarithmically increased in 9 steps from $5 \mathrm{~mm} / \mathrm{yr}$ to $1 \mathrm{~m} / \mathrm{yr}$ and the effective horizontal strain rate was increased up to $10 \times 10^{-3} \mathrm{yr}^{-1}$ with the same spacing as before. Which gives 594 different combinations for the AIS. 
Locations with warmer temperatures and lower accumulation rates than given by these input ranges where not modeled and for the GrIS also places with an average annual melt of more than $1 \mathrm{~mm}$ were excluded. This was done, because in the ablation zone of the polar ice sheets additional processes like melt-water percolation and refreezing contribute to firn densification, which will not be enhanced by strain softening. Drawing conclusions about how strain softening affects the general firn densification process in these areas is therefore not easily possible. To not overestimate the contribution of strain softening in these areas, we decided to restrict our studies to the dry zone of the polar ice sheets by introducing the above restrictions.

The BCO depth and BCO age for the input forcing where then determined from the modeled steady state firn profiles. Local firn properties at every point on the ice sheet were obtained by linear interpolation of the local climatic forcing to the parameter grid. With this approach the ice sheet wide contribution of strain softening to firn densification can be studied by comparing the interpolated firn thickness in the cases of no strain to the case when the uncorrected strain softening model is employed.

Fig. 5 shows for both polar ice sheets the firn thickness when strain softening is considered (a \& d), as well as the absolute (b $\&$ e) and the relative (c \& f) change of the firn thickness with respect to the case of no strain illustrates that strain softening on both ice sheets significantly reduces the firn thickness in the shear margins of ice streams and in the onset regions of the outlet glaciers. A considerable contribution is also observed over the fast flowing Antarctic ice shelves. When looking at the relative firn thinning of the AIS in Fig. 5f, it can moreover be noted that even in the interior of the East Antarctic Ice Sheet (EAIS) strain softening enhances firn densification by up to $10 \%$, despite of low flow velocities and therefore also low horizontal strain rates being present. This unexpected observation can be explained by very low temperatures and accumulation rates occurring in this region, which give rise to extremely low firn densification rates with a $\mathrm{BCO}$ age on the order of $10^{3} \mathrm{yr}$ and in consequence enable strain softening to have a relatively strong impact by being active over a long time span.

Strain softening hence contributes to firn densification over wide areas of the ice sheets. This however does not mean that existing firn densification models, which did not consider strain softening, generally overestimated firn thicknesses, but rather that some contribution of strain softening might have been captured by the model parameters representing the effect of temperature and accumulation rate. The sensitivity of those classical models to the climatic forcing will hence not be accurate. To illustrate this effect, Fig. 5 additionally shows the locations of the firn cores that were used for empirically tuning the HerronLangway model. At least at some of these sites, especially on the AIS, firn thickness is appreciably affected by strain softening. The mean effective horizontal strain rate over all sites where data is available amounts to $4 \times 10^{-4} \mathrm{yr}^{-1}$. Here, the site of the Little America V firn core, which Herron and Langway (1980) already noted to be affected by horizontal stress, is not even included. Consequently, it can be expected that the empirically tuned model parameters for the temperature and accumulation rate dependence implicitly considered strain softening corresponding to an effective horizontal strain rate of $4 \times 10^{-4} \mathrm{yr}^{-1}$.

To take account of this implicit contribution, the previously introduced correction factor was included into the model. However, the correction only works properly at effective horizontal strain rates above $\dot{\varepsilon}_{\text {cor }}$. Below this values the input strain rates can only be reduced to zero, because the effective horizontal strain rate must not be negative. Hence, the correction is not suitable for compensating for the strain softening effect in the HL model in areas with very low strain. To accurately represent 
all three input parameters, i.e. the accumulation rate, the temperature and the effective horizontal strain rate, it is hence required to consider them together during the empirical tuning of the firn model. We leave this to future studies.

Strain rates derived from remotely sensed velocities are sensitive to the degree of smoothing applied. Spatially uncorrelated velocity noise will lead to a positive bias in the effective strain rate. Smoothing reduce the noise amplitude, and will act to lessen this bias. Unfortunately, smoothing will also blur the true strain rate signal leading to a negative bias in the effective strain rate in shear margins. The degree of smoothing is therefore a compromise between reducing noise, and not degrading the signal too much. In this paper, we have chosen the degree of smoothing necessary to remove obvious artefacts. However, in the interior regions with very slow flow the true strain rates may be so small that even a tiny remaining noise amplitude can still be a substantial component of the estimated effective strain rate. This is an important caveat when interpreting the continental scale maps in fig. 5 .

\section{Conclusions}

We have developed a extension for firn densification models that is capable of correcting the densification rate of any climateforced firn model for the effect of strain softening. Employing this model, it was studied how strain softening affects firn densification on local and ice sheet wide scales.

We found that the sensitivity of firn densification to strain softening is highest at low strain rates and that therefore even low strain rates can affect the firn thickness considerably in areas where forcing by accumulation rate and temperature is weak. In high-strain areas, such as the shear margins of ice streams, a significant acceleration of firn densification by strain softening was modeled, which is in good agreement with observed lower firn thickness in these areas. As other potential processes, like horizontal divergence or a greater accumulation in the shear margin troughs, could not explain this reduction of firn thickness, our work supports the idea that strain softening is the principle cause. It was further observed that the change of firn thickness resembles the lowering of the surface elevation in the shear margins, which suggests that the shear margin troughs form because of a faster settling of the firn due to strain softening.

Strain softening not only affects firn thickness, but also reduces the age of the firn at the firn-ice transition. According to our model this can lead to a reduction of the BCO age by around $50 \%$ over a few kilometers in the shear margin of ice streams. We therefore suggest to exploit this feature as a natural laboratory in future firn air studies, because climatic forcing over such 415 small distances will only vary slightly. Moreover, strain softening can strongly alter the BCO age over time, even at constant, moderate strain rates. For ice core dating this induces a bias in the BCO age, which previously has not been considered, but is on an considerable order for synchronizing ice core records by gas isotopes.

Finally, we demonstrate that strain softening has a substantial effect to firn densification over wide areas of ice sheets and as a consequence that horizontal strain rates should generally be considered in firn densification modeling, because a restriction to climatic forcing parameters results in a misrepresentation of the latter. Our work therefore suggests that besides temperature and accumulation rate also the effective horizontal strain rate should be considered as a relevant forcing parameter 
https://doi.org/10.5194/tc-2021-240

Preprint. Discussion started: 22 September 2021

(c) Author(s) 2021. CC BY 4.0 License.

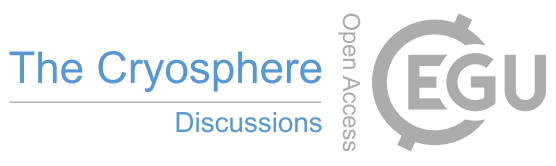

(c) (1)

in firn densification modeling and that all three parameters should already be considered during the empirical tuning of firn densification models.

Code availability. The code for the CFM model with the extension for strain softening is available at https://github.com/oraschewski/ CommunityFirnModel/tree/Falk. The code shall be included into the main CFM repository, when the paper is published.

Author contributions. The idea for the strain softening model extension was developed by both authors. F. Oraschewski carried out the model experiments and wrote the majority of the code and paper, based on his Master's thesis. A. Grinsted acted as a supervisor for the thesis as well as in the preparation of the manuscript.

Competing interests. The authors declare that they have no conflict of interest.

430 Acknowledgements. We acknowledge the Arctic and Climate Research section at the Danish Meteorological Institute for producing and making available their HIRHAM5 model output. For financial support we thank the Villum Investigator Project IceFlow (grant no. 16572) and acknowledge the support of the Studienstiftung des deutschen Volkes to F. Oraschewski. 
https://doi.org/10.5194/tc-2021-240

Preprint. Discussion started: 22 September 2021

(c) Author(s) 2021. CC BY 4.0 License.

(c) (P)

\section{References}

Alley, K. E., Scambos, T. A., Anderson, R. S., Rajaram, H., Pope, A., and Haran, T. M.: Continent-Wide Estimates of Antarctic Strain Rates from Landsat 8-Derived Velocity Grids, Journal of Glaciology, 64, 321-332, https://doi.org/10.1017/jog.2018.23, 2018.

Alley, R. B.: Firn Densification by Grain-Boundary Sliding: A First Model, Journal de Physique Colloques, 48, C1-249-C1-256, https://doi.org/10.1051/jphyscol:1987135, 1987.

Alley, R. B. and Bentley, C. R.: Ice-Core Analysis on the Siple Coast of West Antarctica, Annals of Glaciology, 11, 1-7, https://doi.org/10.3189/S0260305500006236, 1988.

Arnaud, L., Barnola, J. M., and Duval, P.: Physical Modeling of the Densification of Snow/Firn and Ice in the Upper Part of Polar Ice Sheets, in: Physics of Ice Core Records, pp. 285-305, Hokkaido University Press, 2000.

Arthern, R. J., Vaughan, D. G., Rankin, A. M., Mulvaney, R., and Thomas, E. R.: In Situ Measurements of Antarctic Snow Compaction Compared with Predictions of Models, Journal of Geophysical Research, 115, F03 011, https://doi.org/10.1029/2009JF001306, 2010.

Bons, P. D., Kleiner, T., Llorens, M.-G., Prior, D. J., Sachau, T., Weikusat, I., and Jansen, D.: Greenland Ice Sheet: Higher Nonlinearity of Ice Flow Significantly Reduces Estimated Basal Motion, Geophysical Research Letters, 45, 6542-6548, https://doi.org/10.1029/2018GL078356, 2018.

Buizert, C., Cuffey, K. M., Severinghaus, J. P., Baggenstos, D., Fudge, T. J., Steig, E. J., Markle, B. R., Winstrup, M., Rhodes, R. H., Brook, E. J., Sowers, T. A., Clow, G. D., Cheng, H., Edwards, R. L., Sigl, M., McConnell, J. R., and Taylor, K. C.: The WAIS Divide Deep Ice Core WD2014 Chronology - Part 1: Methane Synchronization (68-31 Ka BP) and the Gas Age-Ice Age Difference, Climate of the Past, 11, 153-173, https://doi.org/10.5194/cp-11-153-2015, 2015.

Buizert, C., Fudge, T. J., Roberts, W. H. G., Steig, E. J., Sherriff-Tadano, S., Ritz, C., Lefebvre, E., Edwards, J., Kawamura, K., Oyabu, I., Motoyama, H., Kahle, E. C., Jones, T. R., Abe-Ouchi, A., Obase, T., Martin, C., Corr, H., Severinghaus, J. P., Beaudette, R., Epifanio, J. A., Brook, E. J., Martin, K., Chappellaz, J., Aoki, S., Nakazawa, T., Sowers, T. A., Alley, R. B., Ahn, J., Sigl, M., Severi, M., Dunbar, N. W., Svensson, A., Fegyveresi, J. M., He, C., Liu, Z., Zhu, J., Otto-Bliesner, B. L., Lipenkov, V. Y., Kageyama, M., and Schwander, J.: Antarctic Surface Temperature and Elevation during the Last Glacial Maximum, Science, 372, 1097-1101, https://doi.org/10.1126/science.abd2897, 2021.

Christianson, K., Peters, L. E., Alley, R. B., Anandakrishnan, S., Jacobel, R. W., Riverman, K. L., Muto, A., and Keisling, B. A.: Dilatant till Facilitates Ice-Stream Flow in Northeast Greenland, Earth and Planetary Science Letters, 401, 57-69, https://doi.org/10.1016/j.epsl.2014.05.060, 2014.

Crary, A. P. and Wilson, C. R.: Formation of "Blue" Glacier Ice by Horizontal Compressive Forces, Journal of Glaciology, 3, 1045-1050, https://doi.org/10.3189/S0022143000017445, 1961.

Dee, D. P., Uppala, S. M., Simmons, A. J., Berrisford, P., Poli, P., Kobayashi, S., Andrae, U., Balmaseda, M. A., Balsamo, G., Bauer, P., Bechtold, P., Beljaars, A. C. M., van de Berg, L., Bidlot, J., Bormann, N., Delsol, C., Dragani, R., Fuentes, M., Geer, A. J., Haimberger, L., Healy, S. B., Hersbach, H., Hólm, E. V., Isaksen, L., Kållberg, P., Köhler, M., Matricardi, M., McNally, A. P., Monge-Sanz,

B. M., Morcrette, J.-J., Park, B.-K., Peubey, C., de Rosnay, P., Tavolato, C., Thépaut, J.-N., and Vitart, F.: The ERA-Interim Reanalysis: Configuration and Performance of the Data Assimilation System, Quarterly Journal of the Royal Meteorological Society, 137, 553-597, https://doi.org/10.1002/qj.828, 2011.

Duva, J. M. and Crow, P. D.: Analysis of Consolidation of Reinforced Materials by Power-Law Creep, Mechanics of Materials, 17, 25-32, https://doi.org/10.1016/0167-6636(94)90011-6, 1994. 
https://doi.org/10.5194/tc-2021-240

Preprint. Discussion started: 22 September 2021

(c) Author(s) 2021. CC BY 4.0 License.

(c) (i)

Fahnestock, M. A., Joughin, I., Scambos, T. A., Kwok, R., Krabill, W. B., and Gogineni, S.: Ice-Stream-Related Patterns of Ice Flow in the Interior of Northeast Greenland, Journal of Geophysical Research: Atmospheres, 106, 34035-34045, https://doi.org/10.1029/2001JD900194, 2001.

Fausto, R. S. and van As, D.: Programme for Monitoring of the Greenland Ice Sheet (PROMICE): Automatic Weather Station Data. Version: V03, Dataset published via Geological Survey of Denmark and Greenland, https://doi.org/10.22008/promice/data/aws, 2019.

Fausto, R. S., Box, J. E., Vandecrux, B., Van As, D., Steffen, K., MacFerrin, M. J., Machguth, H., Colgan, W., Koenig, L. S., McGrath, D., Charalampidis, C., and Braithwaite, R. J.: A Snow Density Dataset for Improving Surface Boundary Conditions in Greenland Ice Sheet Firn Modeling, Frontiers in Earth Science, 6, https://doi.org/10.3389/feart.2018.00051, 2018.

Gagliardini, O. and Meyssonnier, A.: Flow Sitnulation of a Firn-Covered Cold Glacier, Annals of Glaciology, p. 7, 1997.

Goldsby, D. L. and Kohlstedt, D. L.: Superplastic Deformation of Ice: Experimental Observations, Journal of Geophysical Research: Solid Earth, 106, 11 017-11 030, https://doi.org/10.1029/2000JB900336, 2001.

Gow, A. J.: Deep Core Studies of the Accumulation and Densification of Snow at Byrd Station and Little America V, Antarctica, Cold Regions Research and Engineering Laboratory (US), 1968.

Greve, R. and Blatter, H.: Dynamics of Ice Sheets and Glaciers, Springer, Berlin, Heidelberg, 2009.

Hansen, N., Langen, P. L., Boberg, F., Forsberg, R., Simonsen, S. B., Thejll, P., Vandecrux, B., and Mottram, R.: Downscaled Surface Mass Balance in Antarctica: Impacts Ofsubsurface Processes and Large-Scale Atmospheric Circulation, Preprint, Ice sheets/Antarctic, https://doi.org/10.5194/tc-2021-69, 2021.

Helsen, M. M., van den Broeke, M. R., van de Wal, R. S. W., van de Berg, W. J., van Meijgaard, E., Davis, C. H., Li, Y., and Goodwin, I.: Elevation Changes in Antarctica Mainly Determined by Accumulation Variability, Science, 320, 1626-1629, https://doi.org/10.1126/science.1153894, 2008.

Herron, M. M. and Langway, C. C.: Firn Densification: An Empirical Model, Journal of Glaciology, 25, 373-385, https://doi.org/10.1017/S0022143000015239, 1980.

Hörhold, M. W., Kipfstuhl, S., Wilhelms, F., Freitag, J., and Frenzel, A.: The Densification of Layered Polar Firn, Journal of Geophysical Research: Earth Surface, 116, n/a-n/a, https://doi.org/10.1029/2009JF001630, 2011.

Horlings, A. N., Christianson, K., Holschuh, N., Stevens, C. M., and Waddington, E. D.: Effect of Horizontal Divergence on Estimates of Firn-Air Content, Journal of Glaciology, 67, 287-296, https://doi.org/10.1017/jog.2020.105, 2021.

Joughin, I., Smith, B. E., Howat, I. M., and Scambos, T. A.: MEaSUREs Multi-Year Greenland Ice Sheet Velocity Mosaic, Version 1., Boulder, Colorado USA. NASA National Snow and Ice Data Center Distributed Active Archive Center, https://doi.org/10.5067/QUA5Q9SVMSJG, 2016.

Joughin, I., Smith, B. E., and Howat, I. M.: A Complete Map of Greenland Ice Velocity Derived from Satellite Data Collected over 20 Years, Journal of Glaciology, 64, 1-11, https://doi.org/10.1017/jog.2017.73, 2018.

Kirchner, J. F., Bentley, C. R., and Robertson, J. D.: Lateral Density Differenences from Seismic Measurements at a Site on the Ross Ice Shelf, Antarctica, Journal of Glaciology, 24, 309-312, https://doi.org/10.3189/S0022143000014829, 1979.

Langen, P. L., Fausto, R. S., Vandecrux, B., Mottram, R. H., and Box, J. E.: Liquid Water Flow and Retention on the Greenland Ice Sheet in the Regional Climate Model HIRHAM5: Local and Large-Scale Impacts, Frontiers in Earth Science, 4, https://doi.org/10.3389/feart.2016.00110, 2017. 
https://doi.org/10.5194/tc-2021-240

Preprint. Discussion started: 22 September 2021

(c) Author(s) 2021. CC BY 4.0 License.

(c) (i)

Licciulli, C., Bohleber, P., Lier, J., Gagliardini, O., Hoelzle, M., and Eisen, O.: A Full Stokes Ice-Flow Model to Assist the Interpretation of Millennial-Scale Ice Cores at the High-Alpine Drilling Site Colle Gnifetti, Swiss/Italian Alps, Journal of Glaciology, 66, 35-48, https://doi.org/10.1017/jog.2019.82, 2020.

Lundin, J. M., Stevens, C. M., Arthern, R., Buizert, C., Orsi, A., Ligtenberg, S. R., Simonsen, S. B., Cummings, E., Essery, R., Leahy, W., Harris, P., Helsen, M. M., and Waddington, E. D.: Firn Model Intercomparison Experiment (FirnMICE), Journal of Glaciology, 63, 401-422, https://doi.org/10.1017/jog.2016.114, 2017.

Lüthi, M. and Funk, M.: Dating Ice Cores from a High Alpine Glacier with a Flow Model for Cold Firn, Annals of Glaciology, 31, 69-79, https://doi.org/10.3189/172756400781820381, 2000.

Maeno, N. and Ebinuma, T.: Pressure Sintering of Ice and Its Implication to the Densification of Snow at Polar Glaciers and Ice Sheets, The Journal of Physical Chemistry, 87, 4103-4110, https://doi.org/10.1021/j100244a023, 1983.

Morris, E. M., Mulvaney, R., Arthern, R. J., Davies, D., Gurney, R. J., Lambert, P., De Rydt, J., Smith, A. M., Tuckwell, R. J., and Winstrup, M.: Snow Densification and Recent Accumulation Along the iSTAR Traverse, Pine Island Glacier, Antarctica, Journal of Geophysical Research: Earth Surface, 122, 2284-2301, https://doi.org/10.1002/2017JF004357, 2017.

Mottram, R., Boberg, F., Langen, P., Yang, S., Rodehacke, C., Christensen, J. H., and Madsen, M. S.: Surface Mass Balance of the Greenland Ice Sheet in the Regional Climate Model HIRHAM5: Present State and Future Prospects, Low Temperature Science, 75, 105-115, https://doi.org/10.14943/lowtemsci.75.105, 2017.

Mouginot, J., Scheuchl, B., and Rignot, E.: Mapping of Ice Motion in Antarctica Using Synthetic-Aperture Radar Data, Remote Sensing, 4, 2753-2767, https://doi.org/10.3390/rs4092753, 2012.

Nye, J. F.: The Distribution of Stress and Velocity in Glaciers and Ice-Sheets, Proceedings of the Royal Society of London. Series A. Mathematical and Physical Sciences, 239, 113-133, https://doi.org/10.1098/rspa.1957.0026, 1957.

Nye, J. F.: A Method of Determining the Strain-Rate Tensor at the Surface of a Glacier, Journal of Glaciology, 3, 409-419, https://doi.org/10.1017/S0022143000017093, 1959.

Oraschewski, F.: Modelling of Firn Densification in the Presence of Horizontal Strain Rates, M.Sc. Thesis, University of Copenhagen, Copenhagen, Denmark, https://doi.org/10.31237/osf.io/fdhxg, 2020.

530 Paden, J., Li, J., Leuschen, C., Rodriguez-Morales, F., and Hale, R.: IceBridge Accumulation Radar L1B Geolocated Radar Echo Strength Profiles, Version 2, https://doi.org/10.5067/0ZY1XYHNIQNY, 2014, updated 2018.

Pedro, J. B., Rasmussen, S. O., and van Ommen, T. D.: Tightened Constraints on the Time-Lag between Antarctic Temperature and $\mathrm{CO}_{2}$ during the Last Deglaciation, Climate of the Past, 8, 1213-1221, https://doi.org/10.5194/cp-8-1213-2012, 2012.

Rignot, E., Mouginot, J., and Scheuchl, B.: Ice Flow of the Antarctic Ice Sheet, Science, 333, 1427-1430, https://doi.org/10.1126/science.1208336, 2011.

Rignot, E., Mouginot, J., and Scheuchl, B.: MEaSUREs InSAR-Based Antarctica Ice Velocity Map, Version 2, https://doi.org/10.5067/D7GK8F5J8M8R, 2017.

Riverman, K. L., Alley, R. B., Anandakrishnan, S., Christianson, K., Holschuh, N. D., Medley, B., Muto, A., and Peters, L. E.: Enhanced Firn Densification in High-Accumulation Shear Margins of the NE Greenland Ice Stream, Journal of Geophysical Research: Earth Surface, 124, 365-382, https://doi.org/10.1029/2017JF004604, 2019.

Salamatin, A. N., Lipenkov, V. Y., and Duval, P.: Bubbly-Ice Densification in Ice Sheets: I. Theory, Journal of Glaciology, 43, 387-396, 1997. 
https://doi.org/10.5194/tc-2021-240

Preprint. Discussion started: 22 September 2021

(c) Author(s) 2021. CC BY 4.0 License.

(c) (i)

Schaller, C. F., Freitag, J., Kipfstuhl, S., Laepple, T., Steen-Larsen, H. C., and Eisen, O.: A Representative Density Profile of the North Greenland Snowpack, The Cryosphere, 10, 1991-2002, https://doi.org/10.5194/tc-10-1991-2016, 2016.

545 Schwander, J., Sowers, T., Barnola, J.-M., Blunier, T., Fuchs, A., and Malaizé, B.: Age Scale of the Air in the Summit Ice: Implication for Glacial-Interglacial Temperature Change, Journal of Geophysical Research: Atmospheres, 102, 19483-19493, https://doi.org/10.1029/97JD01309, 1997.

Simonsen, S. B., Stenseng, L., Ađalgeirsdóttir, G., Fausto, R. S., Hvidberg, C. S., and Lucas-Picher, P.: Assessing a Multilayered Dynamic Firn-Compaction Model for Greenland with ASIRAS Radar Measurements, Journal of Glaciology, 59, 545-558, https://doi.org/10.3189/2013JoG12J158, 2013.

Stevens, C. M., Verjans, V., Lundin, J. M. D., Kahle, E. C., Horlings, A. N., Horlings, B. I., and Waddington, E. D.: The Community Firn Model (CFM) v1.0, Geoscientific Model Development, 13, 4355-4377, https://doi.org/10.5194/gmd-13-4355-2020, 2020.

Svensson, A., Dahl-Jensen, D., Steffensen, J. P., Blunier, T., Rasmussen, S. O., Vinther, B. M., Vallelonga, P., Capron, E., Gkinis, V., Cook, E., Kjær, H. A., Muscheler, R., Kipfstuhl, S., Wilhelms, F., Stocker, T. F., Fischer, H., Adolphi, F., Erhardt, T., Sigl, M., Landais, A., Parrenin, F., Buizert, C., McConnell, J. R., Severi, M., Mulvaney, R., and Bigler, M.: Bipolar Volcanic Synchronization of Abrupt Climate Change in Greenland and Antarctic Ice Cores during the Last Glacial Period, Climate of the Past, 16, 1565-1580, https://doi.org/10.5194/cp-161565-2020, 2020.

Vallelonga, P., Christianson, K., Alley, R. B., Anandakrishnan, S., Christian, J. E. M., Dahl-Jensen, D., Gkinis, V., Holme, C., Jacobel, R. W., Karlsson, N. B., Keisling, B. A., Kipfstuhl, S., Kjær, H. A., Kristensen, M. E. L., Muto, A., Peters, L. E., Popp, T., Riverman, K. L., Svensson, A. M., Tibuleac, C., Vinther, B. M., Weng, Y., and Winstrup, M.: Initial Results from Geophysical Surveys and Shallow Coring of the Northeast Greenland Ice Stream (NEGIS), The Cryosphere, 8, 1275-1287, https://doi.org/10.5194/tc-8-1275-2014, 2014.

Zumberge, J. H., Giovinetto, M., Kehle, R., and Reid, J.: Deformation of the Ross Ice Shelf near the Bay of Whales, Antarctica, no. 3 in IGY Glaciological Report Series, IGY World Data Center A, Glaciology, American Geographical Society, New York, 1960.

Zwinger, T., Greve, R., Gagliardini, O., Shiraiwa, T., and Lyly, M.: A Full Stokes-Flow Thermo-Mechanical Model for Firn and Ice Applied to the Gorshkov Crater Glacier, Kamchatka, Annals of Glaciology, 45, 29-37, https://doi.org/10.3189/172756407782282543, 2007. 
https://doi.org/10.5194/tc-2021-240

Preprint. Discussion started: 22 September 2021

(c) Author(s) 2021. CC BY 4.0 License.

a)

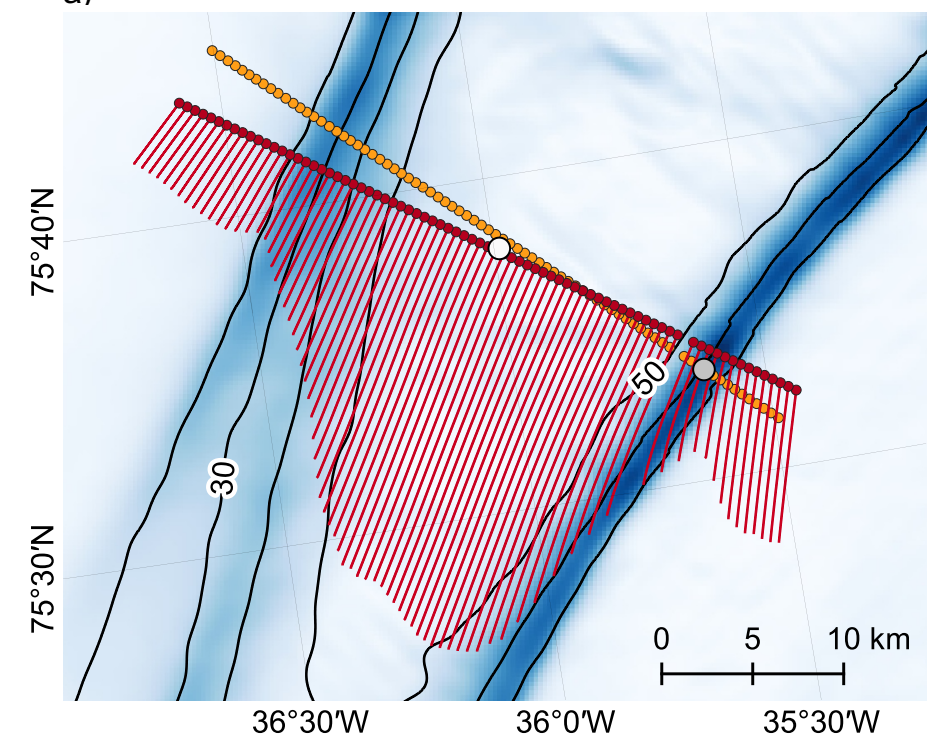

b)
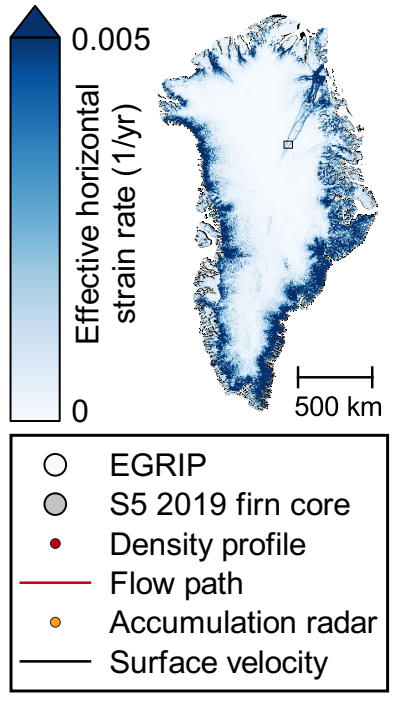

Figure 1. (a) Locations of firn surveys conducted at NEGIS around the EGRIP station. The map shows the sites of the NEGIS firn core (at EGRIP) and the S5 2019 firn core. The red dots indicate the coordinates of the active seismic surveying sites that form the density profile by Riverman et al. (2019) and the yellow dots the corresponding closest points on the accumulation radar line. The red lines indicate the back-traced flow path over firn age at the density profile points. (b) Effective horizontal strain rate over the Greenland Ice Sheet. The black box outlines the extent of (a). 
https://doi.org/10.5194/tc-2021-240

Preprint. Discussion started: 22 September 2021

(c) Author(s) 2021. CC BY 4.0 License.

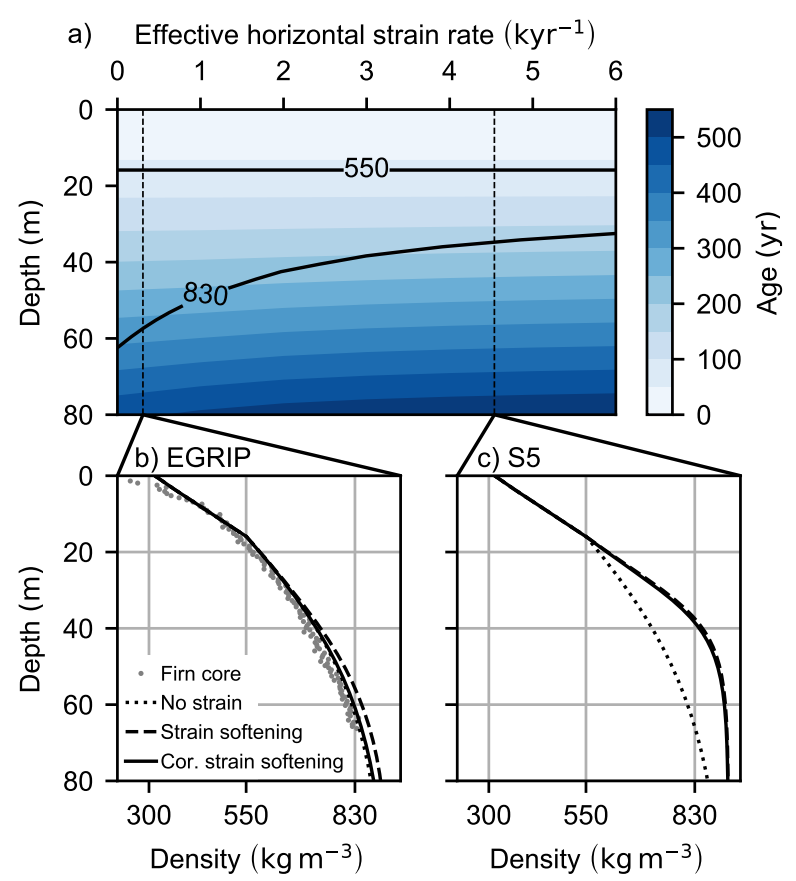

Figure 2. (a) Decreasing sensitivity of firn densification to strain softening for increasing effective horizontal strain rates for climatic conditions present at EGRIP. The background shows the age contours and the black contour lines indicate the critical depth and the depth of the firn-ice transition. Vertical dashed lines indicate the effective horizontal strain rate at the firn core sites in (b) and (c). (b) Firn density data of the NEGIS firn core together with the model for no strain strain softening and a further correction being applied. (c) The same model outputs for the S5 2019 shear margin firn core. 

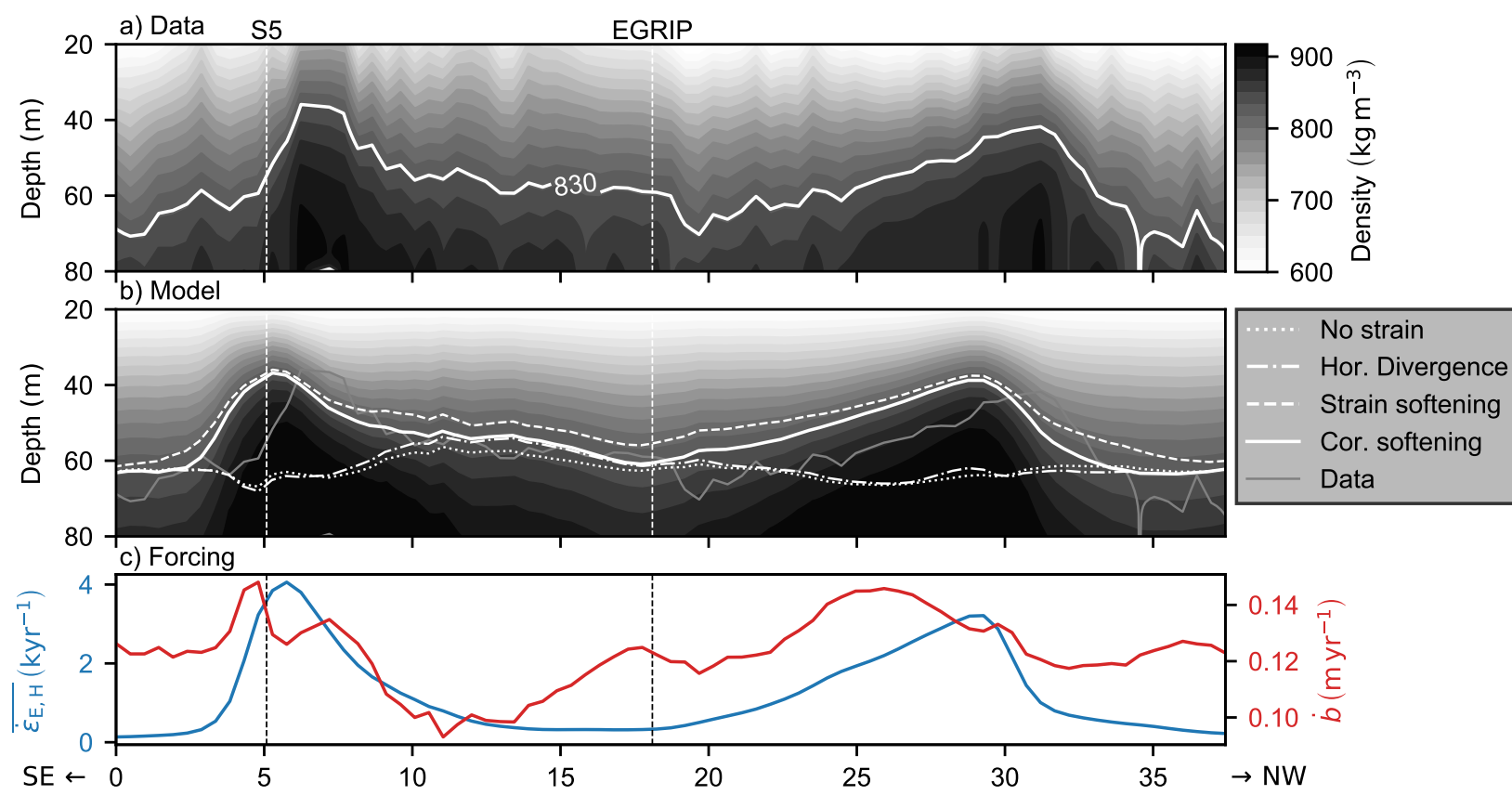

Figure 3. (a) Firn density profile along a cross section of NEGIS recorded by Riverman et al. (2019, Fig. 9b). The white contour line indicates the firn-ice transition. (b) Modeled firn density profile for the same location using the corrected strain softening model. Additionally, the depth of the firn-ice transition for the cases of no strain, horizontal divergence and the uncorrected strain softening model are shown. (c) Mean effective horizontal strain rate over the firn age and the radar derived accumulation rate, which are employed for forcing the model in (b). 
https://doi.org/10.5194/tc-2021-240

Preprint. Discussion started: 22 September 2021

(c) Author(s) 2021. CC BY 4.0 License.
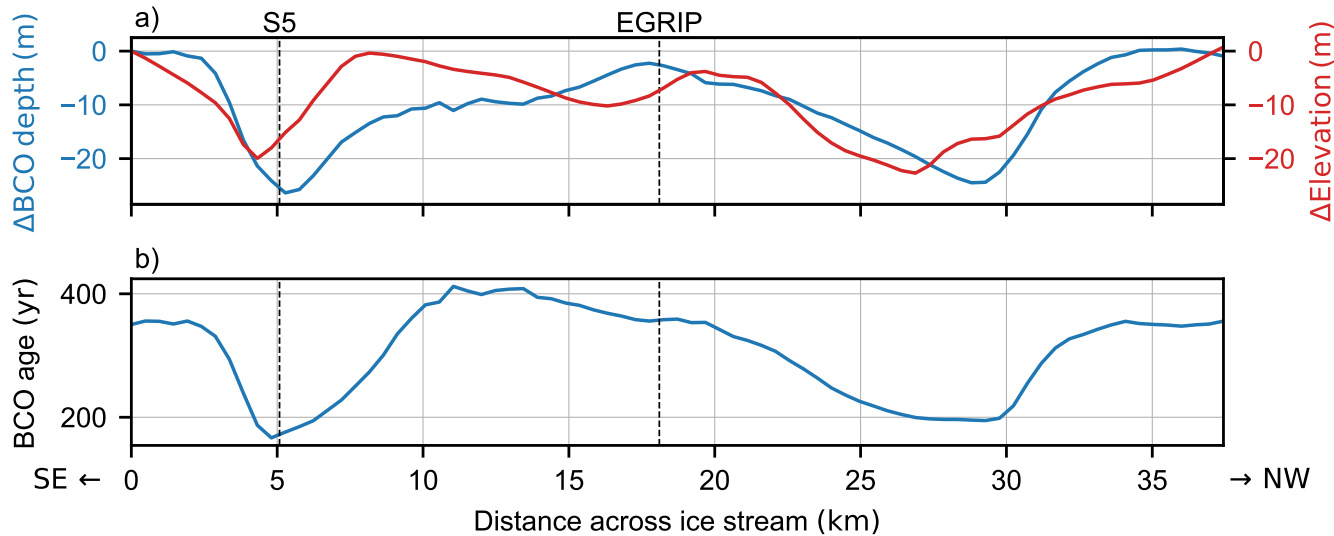

Figure 4. Firn properties along the NEGIS density profile. (a) The change of the bubble-close off (BCO) depth and the surface elevation with respect to the first data point. (b) Age of the firn at bubble-close off. 
https://doi.org/10.5194/tc-2021-240

Preprint. Discussion started: 22 September 2021

(C) Author(s) 2021. CC BY 4.0 License. a) Firn thickness

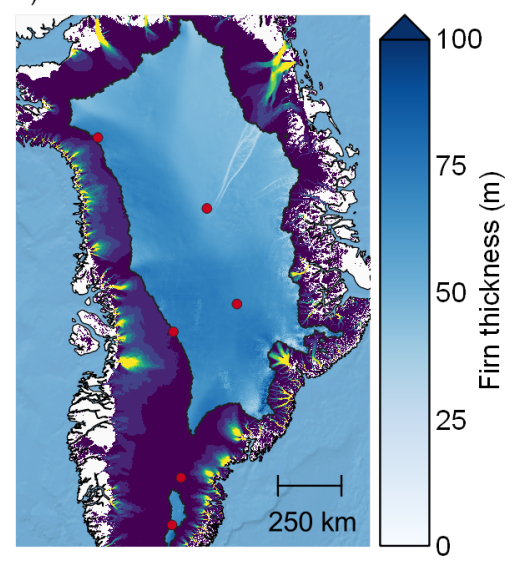

d) Firn thickness

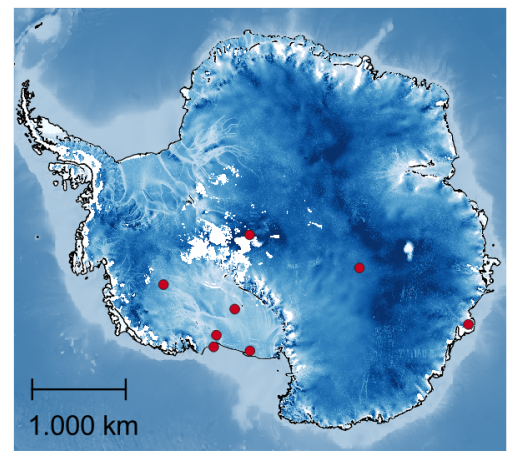

b) Absolute firn thinning

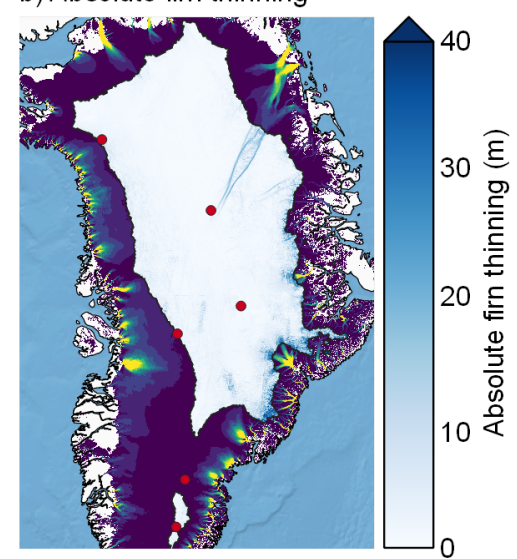

e) Absolute firn thinning

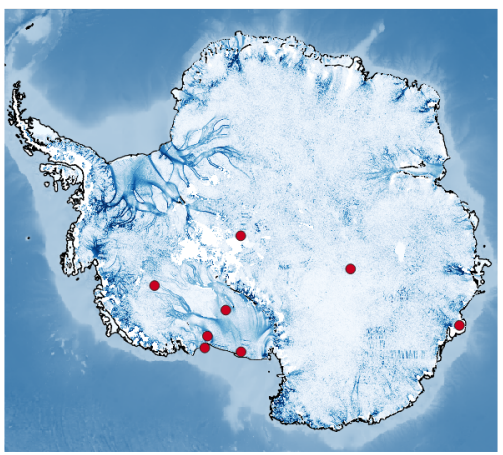

c) Relative firn thinning

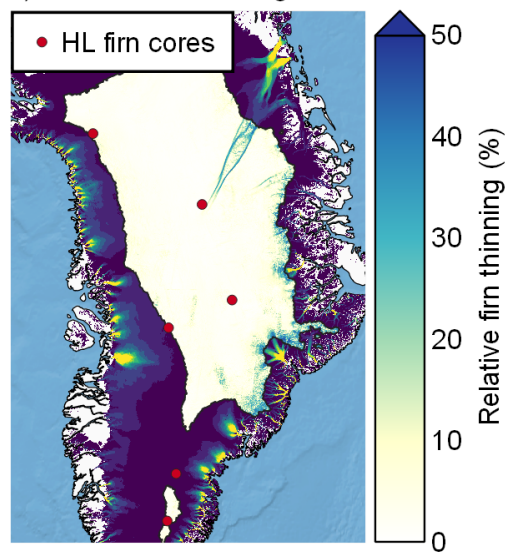

f) Relative firn thinning

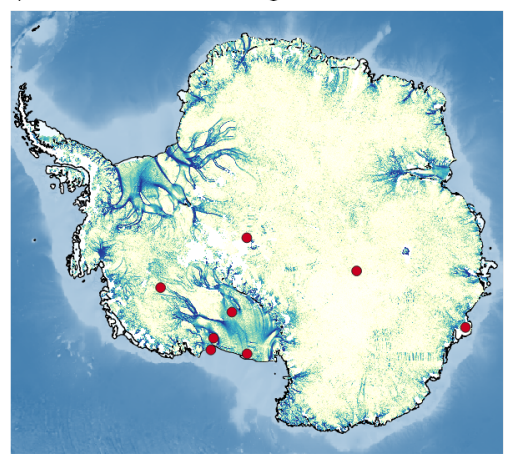

Figure 5. Study how firn thickness is affected by strain softening over the dry zone of the Greenland Ice Sheet (a-c) and the Antarctic Ice Sheet (d-f). (a \& d) Modeled total firn thickness when strain softening is considered. (b \& e) Absolute firn thinning attributed to strain softening. (c \& f) Relative firn thinning, which illustrates the relative contribution of strain softening to the densification process. Red dots indicate the position of the firn cores used for tuning the empirical Herron-Langway model. 